\title{
Rasch Modeling to Drive Instruction of Content Area Concepts and Vocabulary: An Example from Secondary Economics Instruction with Special Needs Students
}

\author{
Cynthia B. Leung, Ph.D. and W. Steve Lang, Ph.D. \\ University of South Florida St. Petersburg \\ St. Petersburg, Florida, USA \\ Steven C. Schaller, M.A. \\ Nassau County School District \\ Fernandina Beach, Florida, USA
}

\begin{abstract}
This study explores the use of Rasch modeling to assess the appropriateness of using unique instructional activities for classroom learning of content vocabulary and concepts. Through a case study of secondary students' learning economics vocabulary from a multimedia instructional activity, the authors identify the difficulty level of key vocabulary items after instruction and estimate the word learning ability of individual students. A teacher of interdisciplinary reading/social studies at an American alternative school for learning and socially challenged adolescents integrated a technology activity into an economics unit. Students in all of his classes created PowerPoint slides for 16 target words and presented them to their peers. Vocabulary knowledge was assessed after the presentations with two teachercreated definition assessments: a matching and a free recall test. Rasch analysis of individual word scores showed creating PowerPoints resulted in many of the words becoming easier, but some of the words remained difficult even after instruction. These vocabulary words and the concepts they refer to may require different instructional strategies for optimum student learning.
\end{abstract}

Keywords: learning disabilities; vocabulary acquisition; adolescents; Rasch modeling; multimedia.

\section{Introduction}

The Rasch model (1960) is an item response theory (RTI) model that places person ability and item difficulty on the same interval scale, called a psychometric "ruler." Using individual calculations of error and fit, rather than the standard error of measurement (SEM), Rasch modeling can determine if predictions are valid for individual examinees or participants. Large sample sizes are not necessary to carry out 
Rasch modeling, and normality of the distribution does not need to be assumed. While Rasch modeling most often is used to provide diagnostic information on how well test items measure particular abilities or traits, it can also be used to assess the difficulty of learning target concepts or vocabulary in particular instructional settings (see Leung \& Lang, 2009 and Leung, Silverman, Nandakumar, Qian, \& Hines, 2011). In this situation, Rasch modeling can estimate an individual's word or concept learning ability from different instructional activities, as well as the difficulty level of different vocabulary words or concepts targeted for learning.

In the present study, a classroom teacher of learning and socially challenged secondary students worked with a literacy researcher and an educational measurement researcher to analyze students' learning of economics content vocabulary. The teacher planned a multimedia project to infuse technology into his integrated literacy and social studies unit on economics. The goal of the activity was to add a hands-on motivating activity for his students to learn key economics terms and concepts they would encounter in their textbook. The research team, which included the classroom teacher, used Rasch modeling to identify the difficulty level of individual economics-related words after instruction in order to evaluate the effectiveness of the instructional activity on meeting curriculum goals. While the focus of this analysis was the learning of students in this particular classroom from participation in the multimedia project, Rasch modeling can be used to evaluate the learning of concepts and vocabulary from any instructional activity in any content area or instructional setting. This article presents a case study of learning economics content vocabulary as an example of how Rasch modeling can be used to evaluate learning for the purpose of driving and improving instruction of particular concepts.

\section{Theoretical Perspectives on Multimedia Learning Cognitive Theory of Multimedia Learning}

Cognitive theories of learning, referred to as the science of learning, have been used to understand multimedia learning. The dual-channel assumption conceptualized by Paivio $(1986,1991)$ to explain mental representations is a central feature of the dualcoding theory. This theory holds that the human information-processing system has two different channels, an auditory/verbal channel and a visual/pictorial channel, and that a combination of verbal and visual information improves processing. At any one time, a limited amount of processing can take place in the verbal or visual channel alone, as explained by Baddeley (1998) in his working memory theory. Meaningful learning takes place through the active processing of verbal and visual channels in working memory and through building connections between verbal and pictorial representations in long-term memory, what Mayer contends is the major assumption in his selecting-organizing- integrating theory of active learning (Mayer, 2008; Mayer \& Moreno, 2003). Mayer developed the cognitive theory of multimedia learning from these most relevant elements of the science of learning - dual channels for processing visual and verbal information, limited capacity of processing, and active processing during learning (Mayer, 2008, 2009). Thus, the five core processes involved in essential processing of multimedia are "selecting words, selecting images, organizing words, organizing images, and integrating" (Mayer \& Moreno, 2003, p. 45). 
Through empirical studies of multiple comparisons of multimedia instructional features, Mayer and his colleagues determined principles for designing effective multimedia learning environments. Mayer's $(2008,2009)$ cognitive theory of multimedia learning along with the instructional design principles he identified as important to multimedia learning are widely recognized as pillars of multimedia learning. Since meaningful learning requires considerable cognitive processing, instructors and instructional designers must be careful not to exceed the learner's cognitive capacity in the design of materials. Cognitive overload is a potential problem that can be reduced by segmenting presentations so the learner has time to organize and integrate the material or, when multimedia includes animation, by presenting words orally as narration rather than as printed words to reduce visual processing. Other techniques Mayer $(2008,2009)$ found to be effective in enhancing learning from multimedia include eliminating extraneous material to make the narration as concise as possible, presenting words and corresponding pictures on the same screen, and simultaneously presenting words and images that go together rather than presenting the words and images successively with narration first and then animation, or vice versa. Also, conversational style in verbal presentation is more effective than formal style. If the multimedia resource, such as an Internet video, cannot be modified but can contribute to learning, students can be instructed before viewing the multimedia on what to focus on, or they can be taught vocabulary and characteristics of essential components if that information is necessary to understand a more complex concept presented in the multimedia.

\section{Constructivist Learning with Technology}

Constructivist theories of learning have emerged across disciplines as a way to understand how to promote substantive and meaningful learning. Much research on constructivist learning through technology is based on seminal works by Dewey (1902, 1938/1997), who advocated for hands-on and experiential learning that would deepen connections between prior knowledge and new knowledge, and by social constructivists like Vygotsky (1978) and Bruner (1960) who emphasized the social nature of learning. All three of these theorists argued that learning is a social and interactive process and that students learn best when they are active participants in the learning process. In classroom settings where teachers apply the constructive view of learning, students are encouraged to construct their own knowledge through inquiry learning activities, such as experiments or real-world problem solving, and then reflect and talk about their understandings. Teachers guide the activities while students categorize and organize information in a process of discovery learning (Bruner, 1961). With adult guidance or collaboration with peers, students can advance their individual learning by working within their zone of proximal development (Vygotsky, 1978).

Process-oriented projects that allow students to explore the Internet have the potential to provide opportunities for meaningful experiential learning. Technologies engage students in authentic tasks where they can apply their own strategies and learning styles. Teachers are better able to differentiate instruction and identify misconceptions as they observe their students working in realistic contexts. Collaborative learning environments centered around computers and other technologies lead to interactive learning where students are transformed from passive recipients of information to active participants in the learning process. From a constructivist perspective, 
"constructing meaning comes from interacting with others to explain, defend, discuss, and assess our ideas and challenge, question, and comprehend the ideas of others" (Sherman \& Kurshan, 2005, p. 12). Technology is a tool for learning that offers a range of instructional options to meet the needs of diverse learners by providing alternatives for mastering concepts and processes (Sherman \& Kurshan, 2004/2005, 2005). Research on teaching to students' learning styles (Silver, Strong, \& Perini, 2000), constructivist theories of learning applied to using technology to create learner-centered classrooms (Sherman \& Kurshan, 2005), and research on building academic language (Zwiers, 2008) support technologies that provide students with multiple learning modalities, especially visual representations.

\section{Psycholinguistic Theories of Active Vocabulary Learning}

In literacy development, active learning has been found to aid in vocabulary acquisition. Channell (1988), a psycholinguist studying second language acquisition, developed a theory of the active role of learners in vocabulary acquisition. She noted that in previous research, associations between the form and meaning of words made by individual learners resulted in successful vocabulary learning. She concluded "learners should be encouraged to make their own lexical associations when they are actively learning new vocabulary" (p. 94). Her theory is compatible with the noticing hypothesis, which when applied to vocabulary learning, suggests memory traces of words are created through interactive learning activities that promote the noticing of particular words (Robinson, 1995). The imageability of words, the degree to which words can elicit mental images, also affects the learning of new vocabulary since the greater the imageability of a word, the greater the chance of it being recalled (Ellis \& Beaton, 1993; Paivio, 1971). Student creation of multimedia materials to acquire new vocabulary involves them in active learning where they focus on particular words, make lexical associations, and find images to help them remember the meaning of words.

\section{Research on Multimedia Learning of Vocabulary}

Multimedia technology plays an important role in creating Computer Assisted Language Learning (CALL) materials, which are used in the teaching of second or other languages, including English. For example, Rusanganwa (2015) studied the effects of a multimedia program created by two English as a Foreign Language (EFL) undergraduate physics teachers in Rwanda on student content vocabulary learning. The program used PowerPoint as a framework to provide access to movies, images, sound recordings, and an online pronouncing dictionary. The study showed the potential of using teacher-created multimedia programs to facilitate technical vocabulary acquisition in one-computer classrooms.

In empirical studies, vocabulary leaning of EFL students has been shown to be enhanced through teacher use of PowerPoints. A study by Nam and Trinh (2012) in two Vietnamese EFL secondary classrooms found the teacher's use of PowerPoints significantly increased English vocabulary learning by providing authentic material in a meaningful context involving sound, pictures, video, and animation. Creative use of PowerPoints in a storytelling approach to teaching English vocabulary significantly increased vocabulary learning of students 8 to 14 years old in a language center in Iran (Kalantar \& Hashemian, 2015). Coleman (2009) reviewed studies of PowerPoint software 
used effectively as an assistive technology to develop reading skills curriculum for individuals with profound communication and cognitive disorders and to reformat texts to make them more accessible for students with various disabilities.

Kennedy, Deshler, and Lloyd (2015) developed multimedia-based instructional modules using PowerPoint, which they called content acquisition podcasts (CAPs), to teach content vocabulary in a world history unit on World War I to high school students, mostly $10^{\text {th }}$ graders, diagnosed with a specific learning disability related to reading as well as their non-learning disabled peers. The researchers followed Mayer's $(2008,2009)$ principles in designing the modules. For research purposes they created four types of CAPs so they could compare four experimental conditions. Thirty vocabulary words became the focus of ten vignettes, with a podcast for each vignette. Students with learning disabilities related to reading who viewed the CAPs with both explicit instruction and the keyword pneumonic strategy had significantly higher scores on two definition tests than those who viewed the CAPs not following Mayer's principles. Both vocabulary tests assessed knowledge of word definitions, one with a multiple choice test and the other with an open-ended format where students were asked to write definitions of the words and any other understanding of the terms. The study shows how PowerPoint can be used to create effective learning materials for students with learning disabilities related to reading.

While teacher-created PowerPoints have been the subject of many research studies (e.g., Coleman, 2009; Gier \& Kreiner, 2009; Savoy, Proctor, \& Salvendy, 2009), few researchers have studied the effects of student creation of PowerPoints on their literacy learning. Curriculum and instruction and instructional design specialists have discussed benefits of having students create their own PowerPoint presentations. These benefits include better understanding of curriculum content and motivating students to learn material that may otherwise be uninteresting (e.g., Ezell, Johnson, \& Rice, 2007; Royer \& Royer, 2002; Sherman \& Kurshan, 2005). Since PowerPoint is widely available, easy to use, and allows for multimodal learning, it has the potential to be used by students at all levels of instruction as a tool for literacy learning.

Research on vocabulary development has shown active and systematic vocabulary instruction can improve vocabulary learning (Beck, McKeown, Kucan, 2013; Blachowicz \& Fisher, 2015; Pearson, Hiebert, \& Kamil, 2007). Recent studies have also explored ways children and adolescents develop vocabulary through the use of various technologies, but this work is in its infancy (Blachowicz, Beyersdorfer, \& Fisher, 2006 for review of studies). Dalton and Gresham (2011) published an article in The Reading Teacher on ways to use technology to build vocabulary. One of their suggestions was for students to use multimedia, such as PowerPoint, to express their vocabulary knowledge. Students could create a multimedia glossary with individual slides for each focus word. The slides could follow a template that includes the word, a short definition of the word, an image representing the word, and the importance of the word or personal associations with the word. Audio recordings, graphics, and other sources could be included in the slide or hyperlinked to it. Classroom teachers are exploring approaches such as this to teach vocabulary. 
Findings from researchers studying second language learning suggest student authoring of hypermedia, sometimes involving PowerPoint, can aid in learning vocabulary in a new language. Pritchard and O'Hara (2009) found 14 English as a second language (ESL) middle school students' scientific vocabulary knowledge developed when the students created PowerPoint slides of vocabulary definitions along with other paper-based vocabulary learning strategies. In another study of 40 Spanish speaking middle school students, O'Hara and Pritchard (2008) found student participation in hypermedia authoring resulted in significant vocabulary gains. Nikolova (2002) had similar results with English speaking college students learning French. Students who linked picture and sound files to target words learned significantly more words than a control group who learned through teacher created hypermedia with hot links.

\section{The Current Study}

The study presented here continues the exploration of students' development of content vocabulary knowledge through their creation of PowerPoint slides for target words. The research team worked together to analyze the effects of students' creation of PowerPoints on their learning the meanings of key vocabulary needed to understand basic economics concepts. The classroom teacher, who taught in an alternative school for adolescents with learning disabilities and social and behavioral challenges, explored ways for his students to learn content vocabulary for concepts presented in an economics textbook by integrating technology into a class assignment. He followed guidelines for integrating technology into literacy instruction for learning disabled youth as suggested by King-Sears and Evmenova (2007). They refer to this process as TECH:

- Target the students' needs and the learning outcome.

- Examine the technology choices, then decide what to use.

- Create opportunities to integrate technology with other instructional activities.

- Handle the implementation, and monitor the impact on the students' learning. (p. 10).

The classroom teacher also applied findings from research on teaching secondary school content to students with learning disabilities. A meta-analysis of special education interventions for secondary content area learning (Scruggs, Mastropieri, Berkeley, \& Graetz, 2010) found that computer-assisted instruction and hands-on activities were effective in increasing content area knowledge for students with learning disabilities. In a review of empirical studies of evidence-based strategies for instruction of older students with learning disabilities, Roberts, Torgesen, Boardman, and Scammacca (2008) concluded that a lack of motivation adversely affects adolescents' abilities to enhance vocabulary and reading comprehension skills. They noted that direct instruction of keywords and a focus on simple definitions, examples and nonexamples, and semantic maps may be especially effective for students with learning disabilities.

The teacher in this study selected the PowerPoint format for the activity because it was an authentic learning activity that was readily available to most of his students and could be accessed in the school's computer lab. As his students developed skill creating PowerPoints, they would become more proficient using the Internet and other literacy 
resources, and their knowledge of PowerPoint creation could be applied to learning how to use other educational technology resources. Students would develop social skills as they worked together, helping each other with their PowerPoints. The teacher could verify his students' understanding of the target vocabulary and correct any misconceptions as he interacted with them when they worked on their PowerPoints. Students would be more motivated to present their ideas to the class with their PowerPoint presentation, and they would be exposed to the target vocabulary multiple times as they viewed their classmates' presentations. Above all, the teacher hoped his students would enjoy their time creating on the computer and searching the Internet.

The purpose of this study was to explore the students' learning of economics vocabulary through their creation and presentation of PowerPoint slides to see if this use of technology would be an effective means to build content vocabulary. The researchers explored the use of Rasch modeling to identify economics words/concepts that remained difficult even after the students had completed the PowerPoint assignment. Through Rasch modeling, the researchers could identify the difficulty levels of target words, from easiest to most difficult, after students created and presented their PowerPoint productions. Words that remained difficult might need adaptations to the PowerPoint assignment or other methods of teaching in order for students to learn these words/concepts. Another purpose of the study was to compare results of two types of vocabulary assessments: a definition assessment with written responses and an assessment to match definitions to terms. This was done to identify words that were most difficult for these students to define in writing and words the students could match easily with definitions but could not define in writing.

\section{Method}

\section{Setting and Participants}

Students who took part in this study were middle school and high school students attending an alternative school in an urban setting in the southeastern United States. The students were all identified as having specific learning disabilities and had behavioral and motivational issues. At this school, students were grouped in classes to maximize learning and for behavior reasons. The teacher had four social studies classes with mixed age students from 7 th to 12th grade: a middle school class, a freshman class, a sophomore class, and a junior/senior class. A total of 41 students, all the students taught social studies by this teacher, participated in the study. The number of students at each grade level was 7 in 7 th grade, 7 in 8 th grade, 9 in 9th grade, 9 in 10th grade, 2 in 11th grade, and 7 in 12th grade. Student data are as follows: 29 male and12 female; 29 European American, 8 African American, 2 Hispanic, and 2 Middle Eastern ethnicities.

\section{Procedure}

The classroom teacher introduced an instructional strategy that combined PowerPoint creation with vocabulary learning to motivate his students to learn about economics concepts. He selected 16 target vocabulary words from the school's economics textbook, Pacemaker ${ }^{\circledR}$ Economics $3 e$ (Pelinski, 2001), which is geared to special needs students. The textbook is written at the 3rd to 4 th grade reading level and is identified as having a lexile level of 870. Note that Lexiles are a form of Rasch Calibration (MetaMetrics, 2017). All target words were in the glossary. Target vocabulary were barter, charity, 
complementary goods, consumer, corporation, currency, financial institution, generic, goods, graph, labor, natural resources, robot, strike, technology, and utility company.

Students each created a PowerPoint with individual slides for individual target words. On each slide students wrote the target word and the definition of the word from the textbook glossary. Students then added visual images to the same slide to demonstrate an understanding of the word. They could paste images from the Internet or draw and scan original drawings or images from magazines. Before starting the project, the teacher introduced the activity by drawing on the board a basic design for the PowerPoint slides, with the word at the top of the slide followed by images and then the definition of the word. He also noted ways students could individualize their PowerPoint, if they chose, by adding transitions, changing the backgrounds, or using other options. Students could work together and could continue working on their PowerPoint outside of school. They were given four weeks to complete the assignment. During the last two weeks of the project, the teacher scheduled time in the computer lab. The teacher assisted any students who needed help scanning images or wanted his assistance in developing their PowerPoint. When the PowerPoints were completed, students presented their PowerPoints to the class, which provided additional exposure to the target words and definitions.

\section{Measure of Intrinsic Motivation}

Since students in this study had motivation issues, the classroom teacher assessed his students' intrinsic motivation, whether they were motivated from within and were interested in and enjoyed the PowerPoint assignment (McGrew, 2008). The teacher developed the assessment by combining selected subscales of the Intrinsic Motivation Inventory (IMI) (Self-Determination Theory, 2017), which is a multidimensional instrument for students to self-report their subjective experiences from participation in particular instructional activities. The IMI is available online and can be modified to fit the particular instructional activity and needs of teachers and researchers. The test items consist of statements that students respond to using a Likert scale. Students indicate how true statements are related to their experiences by assigning a number from 1-7, where 1 = not at all true, $4=$ somewhat true, and 7 = very true. Negative question types are scored in reverse.

The teacher-developed assessment used in this study consisted of three of the seven variables (factors) from the original "Post-Experiential Intrinsic Motivation Inventory." The variables along with related statements were presented in the following order: value/usefulness of the assignment (7 statements), effort/ importance placed on the assignment (5 statements), and interest/enjoyment the students felt towards the assignment (7 statements). Test items included such statements as "This activity was fun to do." and "It was important to me to do well at this task." The motivation assessment was administered on the day students' gave their presentations in order for the teacher to gauge his students' interest in the assignment.

\section{Observation Record}

The classroom teacher took field notes as students worked on their PowerPoints. He focused on students' skills at using computers and the PowerPoint software and on their ability to work together. 


\section{Measures of Vocabulary Learning}

Because of learning difficulties and motivational and behavioral issues, this teacher's students typically would not agree to taking pre- and posttests. Therefore, he had to learn about his students' knowledge and skills through only one administration of any test he created. For this study, students were assessed on the 16 target words with two teacher-created assessments following the presentations: (a) a definitional test where they were asked to define the word and (b) a matching test where they matched definitions with target words. See Figure 1 for the matching test. Each student was assessed on both instruments the day after they completed the four-week assignment. The definition test was administered first, followed by the matching test. Students turned in the definition test when it was completed and then received the matching test. Each correct word received one point, which resulted in a dichotomous score of $0 / 1$ for each word.

Match words with definitions

Barter

Charity

Complementary goods

Consumer

Corporation

_ Currency

Financial institution

Generic

Goods

Graph

Labor

Natural

resource

Robot

Strike

Technology

Utility company a. A bank, credit union, savings and loan, or other organization that offers services related to saving.

b. Goods that are used with each other, such as cars and tires.

c. A business that is owned by stockholders.

d. Without a brand name.

e. Things that can be seen, touched, and bought or sold.

f. The use of science to create new or better goods and services or more efficient methods of production.

g. A work stoppage by labor to win terms of an agreement.

h. Money or A unit of exchange, facilitating the transfer of goods and/or services.

i. A business that provides vital services such as electricity, natural gas, and water

j. Workers

k. A diagram that shows the relationship between two or more sets of things

1. A nonprofit organization that accepts donations such as money, goods, and volunteers time, and then provides aid to needy people

m. The direct exchange of one good or service for another without the use of money.

n. A person who buys goods and services.

o. Something provided by nature, such as wood, oil, and coal, which can be used to produce goods and services.

p. An electronic machine that is programmed to do tasks on an assembly line

Figure 1: Matching Test on Target Vocabulary 


\section{Rasch Modeling}

At the completion of the assignment and administration of assessments, Rasch modeling was carried out using WINSTEPS (Linacre, 2006) software to calibrate words on the two economics definition posttests by level of difficulty. The Rasch method (Rasch, 1960) creates a psychometric "ruler" upon which people and items are placed based on their probability of success. The Rasch ruler is an interval scale (Stevens, 1946) with measurement units called "logits" that are analogous to inches on a wooden ruler. The Lexile Framework, a common measure of readability difficulty, is a Rasch scale (Stenner, 1996, 2001). Rasch modeling was also used to develop the Peabody Picture Vocabulary Test (PPVT-4) now in its fourth edition (Dunn \& Dunn, 2007) and the Expressive Vocabulary Test (EVT-2) now in its second edition (Williams, 2007).

What makes Rasch modeling appropriate for vocabulary research is that it includes people in the measurement process (called conjoint measurement). The ability of participants is put on the same scale as items. It is "the only item response theory (IRT) model in which the total score across items characterizes a person totally" (RUMM, 2017, I 3). Other features of the Rasch model that make it appropriate for vocabulary research are that it "is not sample dependent, does not require a large sample of people, and does not make assumptions about the normality of the distribution. It also works well with missing data" (Wilkerson \& Lang, 2007, p. 315). See Leung and Lang (2009) for a complete discussion of a Rasch model prototype for assessing vocabulary learning.

To find model parameters, the Rasch model provides sophisticated and precise results based on mathematical models for the data. The basic model for dichotomous data is:

$$
\emptyset_{n i l}=\frac{\exp \left(\beta_{n}-\delta_{i 1}\right)}{1+\exp \left(\beta_{n}-\delta_{i l}\right)}
$$

where $\varnothing_{n i l}$ is person $n^{\prime}$ s probability of scoring 1 on item $i, \beta_{n}$ is the ability of person $n$, and $\delta_{i 1}$ is the difficulty level of item $i$. Therefore, the probability of success to answer a question correctly is governed by person ability and item difficulty.

The purpose of the Rasch analysis in this study was to ascertain the difficulty of individual economics words/concepts following instruction. Students were given identification numbers, referred to as person numbers, to be used in the Rasch analysis. For each of the 41 students, the 16 target words were individually scored for the two vocabulary measures explained above. Individual word scores of $0 / 1$ for each word were used in the Rasch analysis. The assessment with written definitions was coded D for each word, and the matching assessment was coded $\mathrm{M}$ for each word.

\section{Results}

\section{Observation Record}

From recorded observations of his students working to create their PowerPoint presentations, the classroom teacher found the older students had more experience with PowerPoint software. A summary of his field notes follows:

The Senior/Junior class had the most experience with the PowerPoint program and helped each other with very little assistance from me. They put more faith in each other's expertise than mine in working with PowerPoint. They took many liberties regarding creativity and showed more skill in manipulating and editing photos for their slides than did the other classes. 
The majority of the sophomore class knew how to use PowerPoint, including the transitions and background choices. They knew how to modify photos pulled off the internet, and by observing their classmates they learned to use the transitions. Almost all of them seemed to enjoy making the slideshow.

The freshman class needed more guidance getting started. Most of the assistance centered on layout and design. They also needed help getting pictures off Internet sites and adjusting them to fit the slides. Once they got the technical aspects of the creation down, they really enjoyed the project, particularly searching for the photos.

The middle school class needed much more scaffolding and guidance. They often needed two or three "walk-throughs" before they gained proficiency with the various processes. Half of the class needed constant guidance and the other half took off on their own and completed the assignment in two or three class periods.

\section{Intrinsic Motivation}

Student responses on the teacher-modified Intrinsic Motivation Inventory indicated students considered statements on the questionnaire to be moderately true or very true. For statements on the value/usefulness of the assignment, $68 \%$ (28 students) found the assignment to be of moderate value and 32\% (13 students) found the assignment to be of high value. For statements on the effort/importance placed on the assignment, 46\% (19 students) put moderate effort into the assignment or placed moderate importance on the assignment and 54\% (22 students) put much effort into or placed much importance on the assignment. Finally, on the interest/enjoyment students felt towards the assignment, one student did not enjoy the assignment, $71 \%$ (29 students) considered the assignment moderately interesting while $27 \%$ (11 students) were highly interested in or greatly enjoyed the assignment. For all but one of the students, intrinsic motivation was at a moderate or high level.

\section{Definition Vocabulary Tests}

Table 1 shows the number and percentage of students who had correct responses on the matching and definition vocabulary assessments. Twenty students could correctly match 13 or more target words with their glossary definitions, and 8 students had all 16 words correct on the matching test. The definition assessment was more difficult with only 3 students being able to define 13 or more target words. However, students represented a wide range of abilities and motivation levels. About half of the students had half of the definitions correct and over $70 \%$ had half of the matching items correct.

Table 1: Number and Percent of Students Having Words Correct on the Definition and Matching Tests

\begin{tabular}{|c|c|c|}
\hline Words Correct & $\begin{array}{l}\text { Definition Test } \\
\mathrm{n} \text { with correct responses }\end{array}$ & $\begin{array}{l}\text { Matching Test } \\
\mathrm{n} \text { with correct responses }\end{array}$ \\
\hline $0-4$ & $6 \quad 15 \%$ & $5 \%$ \\
\hline $5-8$ & $16 \quad 39 \%$ & $922 \%$ \\
\hline $9-12$ & $16 \quad 39 \%$ & $10 \quad 24 \%$ \\
\hline $13-16$ & $\begin{array}{ll}3 & 7 \% \\
\end{array}$ & $20 \quad 49 \%$ \\
\hline
\end{tabular}

\section{Rasch Analysis}

Misfit MNSQ values were observed for persons and items (target words) submitted to the Rasch analysis. All persons and items were within an acceptable range. Model reliability was .87 , which suggests the items created a well-defined scale. A statistically significant difference, $\mathrm{p} .=.004$, existed between scores on the Definition and Matching measures. Pearson correlation for the two assessments was low/moderate at .367. As anticipated, 
writing definitions for targeted economics words was more difficult for these students than matching the words with their glossary meanings. This can be seen on the Rasch ruler in Figure 2 where definition items are higher on the ruler than matching items.

(41 students on left, 16 words on right) Most difficult words are at top of ruler.

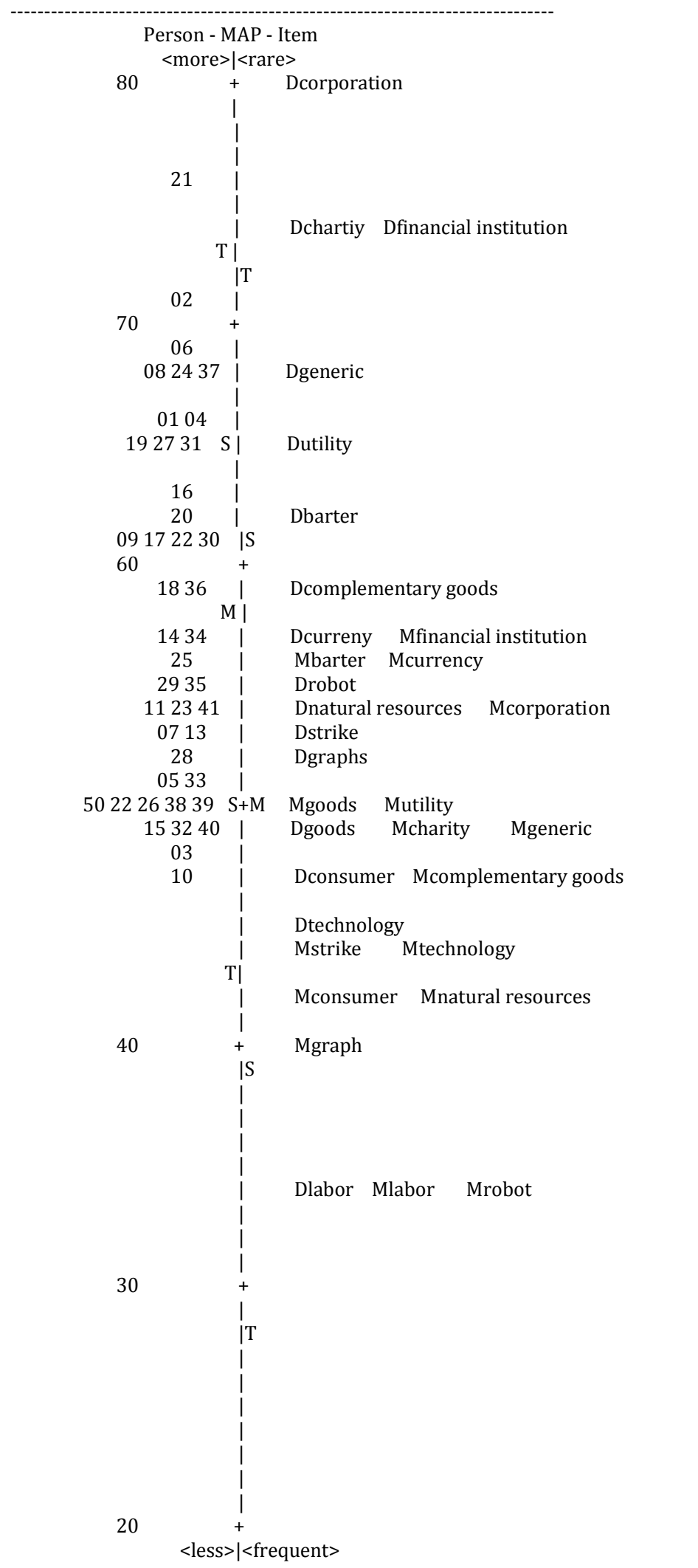

Figure 2: Rasch Ruler for Economics Vocabulary Words ( $D$ = Definition, $M=$ Matching $)$ 
The Rasch ruler calibrates words according to difficulty level, with most difficult words at the top of the map and easiest words at the bottom of the map. The numbers to the left of the map represent persons. The students' ability estimates are left of the center line. It is estimated that students have a .50 probability of knowing words across from their person measure, and a greater probability of knowing words that are below their person measure. $\mathrm{M}$ is the mean, $\mathrm{S}$ is one standard deviation, and $\mathrm{T}$ is two standard deviations. From the Rasch ruler, we can estimate that all the students will be able to define labor, technology, and consumer after creating PowerPoint slides, and they will be able to match definitions to labor, robot, graphs, consumer, natural resources, strike, technology, and complementary goods. These words are ranked as easiest on the Rasch ruler and appear to be words the students may have had some exposure to before working on the PowerPoint project. Defining corporation was a particularly difficult task, and from the Rasch analysis no students were expected to define it. Defining charity, financial institution, and corporation ranked over two standard deviations above the mean. Other difficult words to define that were ranked between one and two standard deviations above the mean were barter, utility, and generic.

Complimentary goods, generic, charity, utility, and corporation were all of average difficulty as identified by the matching assessment, but these words in particular were more difficult to define than to match. It appears that when students were able to match labor, technology, and currency to their definitions, they could also write a definition for those words. Table 1 shows words as they appear on the Rasch ruler, as easier words at the bottom of the ruler, average words in the middle of the ruler, and more difficult words at the top of the ruler. From the table it can be seen that after students participated in the PowerPoint activity including the presentations, only six words remained difficult.

Table 2: Difficulty Levels of Target Economics Vocabulary from Rasch Analysis (D = Definition Assessment, $M=$ Matching Test)

\begin{tabular}{|l|l|l|l|}
\hline $\begin{array}{l}\text { Easy Words } \\
\text { (1 \& 2 SD below }\end{array}$ & $\begin{array}{l}\text { Easier Average Words } \\
\text { (from Mean to1SD } \\
\text { below Mean) }\end{array}$ & $\begin{array}{l}\text { More Difficult Average } \\
\text { Words } \\
\text { (from Mean to 1 SD above } \\
\text { Mean) }\end{array}$ & $\begin{array}{l}\text { Difficult Words } \\
\text { (1 \& 2 SD above Mean) }\end{array}$ \\
\hline $\begin{array}{l}\text { 1 SD below } \\
\text { labor - D } \\
\text { labor - M } \\
\text { robot - M }\end{array}$ & $\begin{array}{l}\text { goods - M } \\
\text { utility - M } \\
\text { goods - D } \\
\text { charity - M } \\
\text { generic - M } \\
\text { consumer - D } \\
\text { complementary goods - M } \\
\text { technology - D } \\
\text { strike - D } \\
\text { technology - M } \\
\text { consumer - M } \\
\text { natural resources - M } \\
\text { graph - M }\end{array}$ & $\begin{array}{l}\text { complementary goods - D } \\
\text { financial institution - M } \\
\text { barter - M } \\
\text { currency - M } \\
\text { robot - D } \\
\text { natural resources - D } \\
\text { corporation - M } \\
\text { strike - D } \\
\text { graphs - D }\end{array}$ & $\begin{array}{l}\text { 2 SD above } \\
\text { corporation -D } \\
\text { charity - D } \\
\text { financial institution - D } \\
\text { 1 SD above } \\
\text { generic - D } \\
\text { utility - D } \\
\text { barter - D }\end{array}$ \\
& & \\
\hline
\end{tabular}

\section{Discussion}

This study shows that adolescents with learning difficulties and behavioral and motivational issues can develop content vocabulary and concepts by creating and presenting PowerPoint slides of content words from textbook glossaries, in this case 
economics terms. Illustrating economics terms and definitions with pictures from the internet or scanned from magazines resulted in most of the students learning some target vocabulary and some students learning all the vocabulary. Focusing on definitions and illustrations of concepts can help students understand terms they read, but they may need additional practice or different learning strategies to be able to write definitions for some difficult content vocabulary.

However, some glossary items in the economics textbook written at a 3 rd to 4 th grade reading level, along with the discussion in the textbook, may not have provided enough information for students to understand some of the concepts. For example, the definition of corporation in the glossary was "a business that is owned by stockholders." In their PowerPoint presentations, most students illustrated the slide for corporation with pictures of the front of buildings that displayed the names of corporations. This provided an overly simplified illustration to explain the glossary definition. In order to more fully understand what corporations are and what they by law can do, students would need to understand other related concepts, including stock, shareholders, dividends, limited liability, contracts, management, and Board of Directors. A different instructional strategy such as role playing may help students better understand what a corporation is. Students could set up their own corporation with a Board of Directors and stockholders. By acting out the roles of people involved in a corporation, students could acquire a deeper understanding of corporation. Also, business simulations are available online for game participants to create companies, buy and sell shares of stock, and react to daily news postings. Some examples of simulation game websites are simCEO (https://www.simceo.org/action/welcome) (Jetlag Learning, 2017), and Tycoon Games (https://www.learn4good.com/games/tycoonbusiness.htm) (Learn4Good, 2017), which offers a number of simulations for students at different age levels. These simulations provide learning opportunities for students to reason for authentic purposes.

\section{Conclusion}

While this study focused on economics vocabulary and students with special needs, the application of Rasch modeling developed for this context can be applied to any content areas where students are learning new technical or academic vocabulary and concepts or with any groups or classifications of students. Through Rasch analysis instructors can identify words or concepts that are difficult for their particular students to learn, and they can evaluate the degree of learning assessed by various measures. Literacy researchers are exploring ways to measure word difficulty and to identify words and concepts that are easier or more difficult for students at different ages to learn (Leung \& Lang, 2009; Leung, Silverman, Nandakumar, Qian, \& Hines, 2011). The Rasch model provides a way to measure word difficulty while at the same time taking into consideration the ability of individuals to learn vocabulary. These statistical measures have the potential to make clearer the process of learning academic vocabulary from participation in technology rich classrooms. If classroom teachers can look at the results of Rasch analyses to rank content area vocabulary and understand which terms and concepts are easiest and most difficult for their students to learn by different instructional strategies, they can plan their curriculum to include technology-enhanced instruction, such as student PowerPoint creation, for words and concepts appropriate for students to learn with this medium. For concepts that are more difficult, they can provide additional instruction through different activities that may lead to deeper understanding. 


\section{References}

Baddeley, A. (1998). Human Memory. Boston: Allyn \& Bacon.

Beck, I. L., McKeown, M. G., \& Kucan, L. (2013). Bringing words to life: Robust vocabulary instruction (2nd ed.). New York: Gilford Press.

Blachowicz, C., \& Fisher, P. J. (2015). Teaching vocabulary in all classrooms (5th ed.). Boston: Pearson Education.

Blachowicz, C. L. Z., Beyersdorfer, J., \& Fisher, P. (2006). Vocabulary development and technology: Teaching and transformation. In M. C. McKenna, L. D. Labbo, R. Kieffer, \& D. Reinking (Eds.), International handbook of literacy and technology (Vol. 2, pp. 341-348). Hillsdale, NJ: Erlbaum.

Bruner, J. S. (1960). The process of education. Cambridge, MA: Harvard University Press.

Bruner, J. S. (1961). The act of discovery. Harvard Educational Review, 31, 21-32.

Channell, J. (1988). Psycholinguistic considerations in the study of L2 vocabulary acquisition. In R. A. Carter \& M. J. McCarthy (Eds.). Vocabulary and language teaching. London: Longman.

Coleman, M. B. (2009). "PowerPoint" is not just for business presentations and college lectures: Using "PowerPoint" to enhance instruction for students with disabilities. Teaching Exceptional Children Plus, 6(1), 2-13. Retrieved from http://www.eric.ed.gov/PDFS/EJ875424.pdf

Dalton, B., \& Grisham, D. L. (2011). eVoc strategies: 10 ways to use technology to build vocabulary. The Reading Teacher, 64(5), 306-317. doi:10.1598/RT.64.5.1

Dewey, J. (1902). The child and the curriculum. Chicago: University of Chicago Press.

Dewey, J. (1938/1997). Experience and education. New York: Simon \& Schuster.

Dunn, L. M., \& Dunn, D. M. (2007). Peabody Picture Vocabulary Test, Fourth Edition (PPVTTM_4). New York: Pearson Clinical.

Ellis, N. C., \& Beaton, A. (1993). Psycholinguistics determinants of foreign language vocabulary learning. Language Learning, 43, 559-617. doi: 10.1111/j.1467-1770.1993.tb00627.x

Ezell, B. R., Johnson, D. D., \& Rice, M. P. (2007). Developing student assignments that require the creation of PowerPoint presentations: A six step model. Proceedings of the Society for Information Technology and Teacher Education (SITE 2007), pp. 2554-2557. Chesapeake, VA: SITE.

Gier, V. S., \& Kreiner, D. S. (2009). Incorporating active learning with PowerPoint-based lectures using content-based questions. Teaching of Psychology, 36, 134-139. doi:10.1080/00986280902739792

Jetlag Learning. (2017). SimCEO: Classroom economy online. Retrieved from https://www.simceo.org/action/welcome

Kalantar, F., \& Hashemian, M. (2015). A story-telling approach to teaching English to young Iranian learners. English Language Teaching, 9(1), 221-234.

Kennedy, M. J., Deshler, D. D., \& Lloyd, J. W. (2015). Effects of multimedia vocabulary instruction on adolescents with learning disabilities. Journal of Learning Disabilities, 48, 22-38. doi:10.1177/0022219413487406

King-Sears, M. E., \& Evmenova, A. S. (2007). Premises, principles, and processes for integrating TECHnology into instruction. Teaching Exceptional Children, 40(1), 6-14. doi:10.1177/004005990704000101

Learn4Good. (2017). Tycoon games/Business simulations for kids/teens/students. Retrieved from https://www.learn4good.com/games/tycoonbusiness.htm

Leung, C. B., \& Lang, W. S. (2009). A Rasch Model prototype for assessing vocabulary learning resulting from different instructional methods: A preschool example. Journal of Applied Measurement, 10(1), 70-83.

Leung, C. B., Silverman, R., Nandakumar, R., Qian, X., \& Hines, S. (2011). A comparison of difficulty levels of vocabulary in first-grade basal readers for preschool dual language learners and monolingual English learners. American Educational Research Journal, 48, 421461. doi:10.3102/0002831210382890

Linacre, J. M. (2006). A user's guide to WINSTEPS and MINISTEPS: Rasch model computer programs. Chicago: Winsteps.com. 
Mayer, R. E. (2008). Applying the science of learning: Evidence-based principles for the design of multimedia instruction. American Psychologist, 63, 760-769. doi:10.1037/0003-066X.63.8.760

Mayer, R. E. (2009). Multimedia learning (2nd ed.) New York: Cambridge University Press.

Mayer, R. E., \& Moreno, R. (2003). Nine ways to reduce cognitive load in multimedia learning. Educational Psychologist, 38, 43-52. doi:10.1207/S15326985EP3801_6

McGrew, K. (2008). Intrinsic motivation. Beyond IQ: A model of academic competence \& motivation (MACM). Institute for Applied Psychometrics. Retrieved from http://www.iapsych.com/acmcewok/Intrinsicmotivation.html

MetaMetrics. (2017). The lexile framework for reading: Lexile research. Retrieved from https://lexile.com/research/category/3/

Nam, T. T., \& Trinh, 1. Q. (2012). PowerPoint as a potential tool to learners' vocabulary retention: Empirical evidences from a Vietnamese secondary education setting. Journal on English Language Teaching, 2(4), 15-22.

Nikolova, O. R. (2002). Effects of students' participation in authoring of multimedia materials on student acquisition of vocabulary. Language Learning $\mathcal{E}$ Technology, 6(1), 100-122.

O'Hara, S., \& Prichard, R. (2008). Hypermedia authoring as a vehicle for vocabulary development in middle school English as a second language classrooms. The Clearing House, 82(2), 60-65. doi:10.3200/TCHS.82.2.60-65

Paivio, A. (1971). Imagery and verbal processes. New York: Holt, Rinehart, \& Winston.

Paivio, A. (1986). Mental representations: A dual coding approach. Oxford, UK. Oxford University Press.

Paivio, A. (1991). Dual coding theory: Retrospect and current status. Canadian Journal of Psychology, 45, 255-287.

Pearson, P. D., Hiebert, E. H., \& Kamil, M. L. (2007). Vocabulary assessment: What we know and what we need to know. Reading Research Quarterly, 42, 282-296. doi:10.1598/RRQ.42.2

Pelinski, J. (2001), Pacemaker ${ }^{\circledR}$ Economics 3e. New York: Globe Fearon/Pearson Education. Information on textbook available from https:// www.pearsonschool.com/index.cfm?locator=PSZu72\&PMDBSUBCATEGORYID= \&PMDBSITEID $=2781 \&$ PMDBSUBSOLUTIONID $=\&$ PMDBSOLUTIONID $=6724 \&$ PMDBSUB JECTAREAID $=\&$ PMDBCATEGORYID=1662\&PMDbProgramId $=27041$

Pritchard, R., \& O'Hara, S. (2009). Vocabulary development in the science classroom: Using hypermedia authoring to support English learners. The Tapestry Journal, 1(1), 15-29.

Rasch, G. (1960). Probabilistic models for some intelligence and attainment tests. Copenhagen: Danmarks Paedogogiske Institut. (Chicago: University of Chicago Press, 1980)

Roberts, G., Torgesen, J. K., Boardman, A., \& Scammacca, N. (2008). Evidence-based strategies for reading instruction of older students with learning disabilities. Learning Disabilities Research E Practice, 23(2), 63-69. doi: 10.1111/j.1540-5826.2008.00264.x

Robinson, P. (1995). Review article: Attention memory and the "noticing" hypothesis. Language Learning, 45, 283-331. doi: 10.1111/j.1467-1770.1995.tb00441.x

Royer, R., \& Royer, J. (2002). Developing understanding with multimedia: Putting the tools of multimedia development into the hands of students can deepen the educational experience. Learning \& Leading with Technology, 29(7), 40-45.

RUMM. (2017). Rasch analysis. RUMM 2020 Laboratory website. Retrieved from http://www.raschanalysis.com/rasch-analysis.htm

Rusanganwa, J. A. (2015) Developing a multimedia instrument for technical vocabulary learning: A case of EFL undergraduate physics education. Computer Assisted Language Learning, 28, 97111, doi:10.1080/09588221.2013.784708

Savoy, A., Proctor, R. W., \& Salvendy, G. (2009). Information retention from PowerPoint[TM] and traditional lectures. Computers \& Education, 52, 858-867. doi:10.1016/j.compedu.2008.12.005

Scruggs, T. E., Mastropieri, M. A., Berkeley, S., \& Graetz, J. E. (2010). Do special education interventions improve learning of secondary content? A meta-analysis. Remedial and Special Education, 31, 437-449. doi:10.1177/0741932508327465

Self-Determination Theory (SDT). (2017). Intrinsic Motivation Inventory. Retrieved from http://selfdeterminationtheory.org/intrinsic-motivation-inventory/

Sherman, T. M., \& Kurshan, B. L. (2004/2005). Teaching for understanding. Learning and Leading with Technology, 32(4), 6-11. 
Sherman, T. M., \& Kurshan, B. L. (2005). Constructing learning: Using technology to support teaching for understanding. Learning and Leading with Technology, 32(5), 10-39.

Silver, H. F., Strong, R. W., \& Perini, M. J. (2000). So each may learn: Integrating learning styles and multiple intelligences. Alexandria, VA: Association for Supervision and Curriculum Development.

Stenner, A. J. (1996). Measuring reading comprehension with the Lexile Framework. Durham, NC: MetaMetrics.

Stenner, A.J. (2001). The Lexile Framework: A common metric for matching readers and texts. California School Library Journal, 25(1): 41-42.

Stevens, S. S. (1946). On the theory of scales of measurement. Science, 103, 677-680.

Vygotsky, L. A. (1978). Mind in society: The development of higher psychological processes. Cambridge, MA: Harvard University Press.

Wilkerson, J., \& Lang, S. (2007). Assessing teacher competency: Five standards-based steps to valid measurement using the CAATS Model. Thousand Oaks, CA: Corwin Press.

Williams, K. T. (2007). Expressive Vocabulary Test, Second Edition (EVT-2). New York: Pearson Clinical.

Zwiers, J. (2008). Building academic language: Essential practices for content classrooms, grades 5-12. San Francisco: Jossey-Bass. 